\title{
Long-Range Distance Determination in a DNA Model System inside Xenopus laevis Oocytes by In-Cell Spin-Label EPR
}

\author{
Mykhailo Azarkh, Oliver Okle, Vijay Singh, Isabelle T. Seemann, Jörg S. Hartig, Daniel R. Dietrich, and \\ Malte Drescher*[a]
}

Elucidating the structure and dynamics of biomacromolecules, for example, proteins, RNA, or DNA, is crucial for understanding their physiological function. Beside widespread techniques, such as NMR spectroscopy or crystallography, sophisticated electron paramagnetic resonance spectroscopy (EPR) methods in combination with site-directed spin labeling ${ }^{[1]}$ are receiving increasing attention for this purpose. Spin-label EPR (SL-EPR) offers access to structural information on a length scale between approximately 0.5 and $10 \mathrm{~nm}$, and enables the study of dynamics in the pico- to microsecond range. ${ }^{[2-8]}$ To date, SLEPR has been carried out in defined buffer solutions. However, recently an in-cell SL-EPR experiment investigating the conformation of ubiquitin was reported; ${ }^{[9]}$ this suggests that the technique can be applied to nucleic acids as well, which is of particular importance since non-canonical DNA conformations are involved in many processes, such as regulatory functions. The development of analytical tools for elucidating native structures inside cells is an ongoing challenge to be addressed by in-cell spectroscopy. ${ }^{[10]}$ Here, we describe long-range distance measurements on a DNA model system in oocytes of Xenopus laevis utilizing in-cell EPR.

Compared to in-cell NMR spectroscopy, in-cell EPR has two main advantages. Low concentrations can be used because EPR is much more sensitive per spin than NMR spectroscopy, and since EPR only detects unpaired electron spins no background from diamagnetic molecules is observed. The latter is of particular importance since in contrast to structural studies of isolated macromolecules, in-cell experiments are often hampered by many different cellular components and thereby provide for high background signals. On the other hand, in-cell studies are of greater significance since, in contrast to pure solution experiments, a natural environment is provided, which can be crucial for observing the biologically relevant conformation of biomacromolecules. ${ }^{[11,12]}$

Double electron-electron resonance (DEER or PELDOR) is a pulsed, two-frequency EPR technique for determining distance distributions (from 1.5 up to $8 \mathrm{~nm}$ ) between two paramagnetic centers by measuring their dipole-dipole interaction. ${ }^{[13-15]}$ Diamagnetic biomacromolecules can be site-directly labeled with nitroxides. $^{[1]}$

[a] M. Azarkh, O. Okle, Dr. V. Singh, I. T. Seemann, Prof. Dr. J. S. Hartig, Prof. Dr. D. R. Dietrich, Dr. M. Drescher

Departments of Chemistry and Biology

Konstanz Research School Chemical Biology, and Zukunftskolleg

University of Konstanz, 78457 Konstanz (Germany)

E-mail:Malte.Drescher@uni-konstanz.de
To demonstrate the feasibility and potential of in-cell DEER for studying DNA, a model system consisting of a spin-labeled double helix was delivered into Xenopus oocytes. These eukaryotic cells are often used for intracellular experiments, ${ }^{[16]}$ their large size (about $1 \mathrm{~mm}$ in diameter) allows for deposition of spin labeled molecules by microinjection. ${ }^{[17]}$ DNA constructs were injected into the animal hemisphere cytoplasm of stage $\mathrm{VI}$ oocytes, where nucleus-like conditions preside, ${ }^{[18]}$ thus remaining enzymatically unchallenged within the cytoplasm of the unfertilized oocyte. ${ }^{[19]}$

To characterize $X$. laevis oocytes as a suitable system for incell DEER we injected TOAC spin probes (2,2,6,6-tetramethylpiperidine- $\mathrm{N}$-oxyl-4-amino-4-carboxylic acid) containing a nitroxide radical, which is structurally similar to the spin label used for labeling the DNA duplex. The stock solution ( $4 \mathrm{~mm}$ ) was injected $(50 \mathrm{~nL})$ into each cell followed by shock freezing in liquid nitrogen.

In-cell continuous wave EPR spectra (Figure $1 \mathrm{~A}$ ) resulted in an $A_{\mathrm{zz}}$ value of the hyperfine splitting, which was $7.6 \mathrm{MHz}$ lower than the aqueous solution, indicating a lower polarity in the cytoplasm. The uninjected oocytes showed an EPR signal that overlapped with the central $m_{1}=0$ line of the nitroxide, while oocyte cell extracts were EPR silent. This intrinsic signal is weaker than the signal of the injected nitroxide by a factor of 50 (Figure $1 \mathrm{~A}$ ), and can be eliminated by background correction within the analysis of the DEER curves.

Since spin labels are not stable under the reducing conditions in cells, time dependent in-cell EPR experiments were performed (Figure 1B). The half-life analysis of TOAC in oocytes at room temperature resulted in $t_{1 / 2}=1.1( \pm 0.4) \mathrm{min}$. In experiments for distance measurements, shock-freezing of oocytes immediately (ca. $10 \mathrm{~s}$ ) after injection was carried out in order to conserve a sufficient degree of labeling and to trap the macromolecular conformations.

For microinjection two complementary strands d[TATCGAA] and d[TTCGATA], each labeled with TEMPA at the $5^{\prime}$-end thymidine (shown in bold) were synthesized. ${ }^{[20]}$ DEER experiments were performed at $T=45 \mathrm{~K}$ by using an ELEXSYS E580 spectrometer (Bruker BioSpin) operated in X-Band $(9.4 \mathrm{GHz})$. Data were analyzed by using DEERAnalysis2010 software package. ${ }^{[21]}$

Taking a B-form DNA double helix conformation into account, the label-label distance is predicted as $3.0 \mathrm{~nm}$ (Figure S2 in the Supporting Information). The distance constraint obtained by the DEER experiment in buffered solution corresponds to $d=3.20 \mathrm{~nm}$ (Figure 2, Table 1). The DEER data show a modulation depth that is shallower than expected for a $12 \mathrm{~ns}$ pump pulse. This suggests partial reduction of spin labels during synthesis and a resulting incomplete labeling, however, without infringing reliable data analysis. ${ }^{[4,20]}$ In general, the 


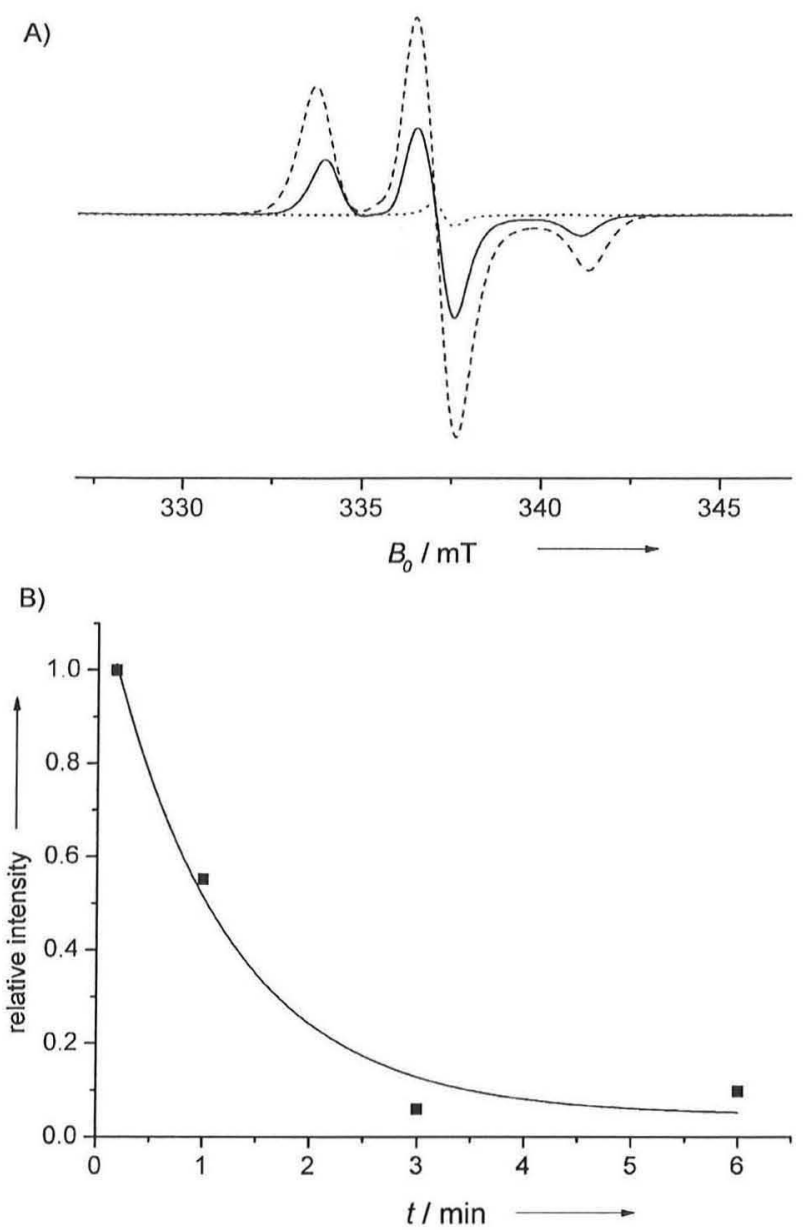

Figure 1. A) EPR spectra of TOAC ( $4 \mathrm{~mm}$ ) in frozen buffer solution (-..--), injected into cells $(\longrightarrow)$ and EPR spectrum of cells before injection $(\cdots . .$.$) .$ B) EPR signal intensity of TOAC versus delay between microinjection and shock-freezing (a) and exponential fit (-).

width of the distance distribution (Figure S1 in the Supporting Information) reflects both the flexibility of the macromolecule under study as well as the reorientational degree of freedom of the attached spin label, ${ }^{[22]}$ while the errors of EPR distance measurements are much smaller than the variation of the distances due to conformational distribution. ${ }^{[15]}$ Here, the narrow distance distribution $(\sigma=0.43 \mathrm{~nm})$ in combination with the distance constraint $d$ represents a completely hybridized DNA duplex.

For the in-cell DEER experiments $50 \mathrm{~nL}$ DNA solution $(4 \mathrm{~mm})$ was injected into each oocyte. The resulting local concentration of spin labels was lowered during the delay between injection and shock-freezing due to translational diffusion and limited label lifetime. The local concentration was determined to be $220 \mu \mathrm{m}$ by a rough estimation utilizing the background function. ${ }^{[21]}$ The chosen concentration corresponded to the optimum under our conditions in order to balance signal-to-noise ratio and the ratio between intramolecular dipolar contribution and intermolecular background. ${ }^{[15]}$ Sixty oocytes containing spin-labeled DNA filling a $3 \mathrm{~mm}$ inner diameter tube to the


Figure 2. DEER curve of spin-labeled DNA duplex in buffer: A) before background correction $(\mathrm{O})$ and background fit $(-), \mathrm{B})$ after background correction (o), model-free fit by using Tikhonov regularization (-).

\begin{tabular}{|c|c|c|c|c|c|}
\hline Experiment $^{[a]}$ & $d[\mathrm{~nm}]$ & $\sigma[\mathrm{nm}]$ & Experiment $^{[a]}$ & $d[\mathrm{~nm}]$ & $\sigma[\mathrm{nm}]$ \\
\hline buffer (MS-3) & 3.20 & 0.43 & in-cell (MD-4) & 3.22 & 1.04 \\
\hline
\end{tabular}

height of about $7 \mathrm{~mm}$ were used for the in-cell DEER experiment.

The use of a dielectric resonator (MD4) offers a larger sample volume compared to the split ring resonator (MS3) often used for conventional DEER experiments, and enabled us to improve the signal-to-noise ratio (see the Supporting Information). A DEER trace corresponding to a dipolar evolution of $1 \mu$ s was recorded (Figure 3 ).

The loss of modulation depth between the measurements in buffer and in the cell was approximately $50 \%$. Since also a reduced signal-to-noise ratio was observed, in cellulo, the lower modulation depth is likely as a result of nitroxide reduction inside cells, which occurred during the time between microinjection and freezing. The latter reduced the fraction of 

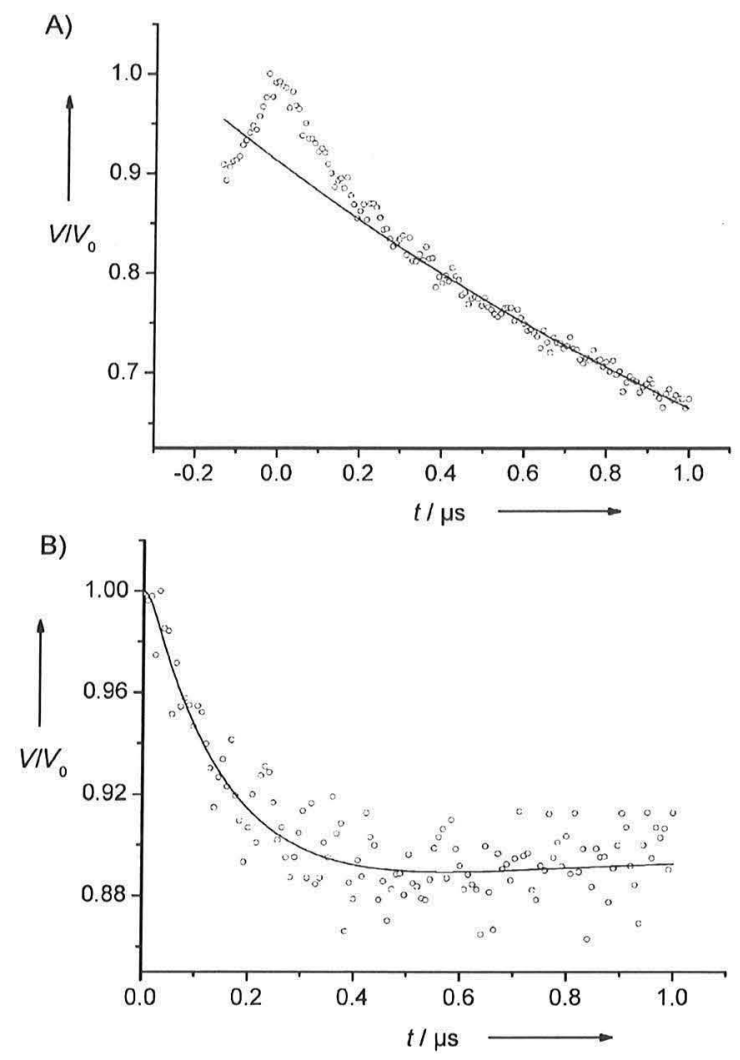

Figure 3. In-cell DEER curve of spin-labeled DNA duplex: A) before background correction (O) and background fit (-), B) after background correction (O), and model-free fit by using Tikhonov regularization $(\longrightarrow$ ).

(doubly) spin-labeled species. The in-cell distance distribution corresponds to a distance constraint $d=3.22 \mathrm{~nm}$, which is in agreement with the theoretically predicted as well as with the experimentally obtained values for the isolated duplex in buffer.

However, the in-cell distance distribution is broader $(\sigma=$ $1.04 \mathrm{~nm}$; Figure S1 in the Supporting Information, Table 1) than that measured in vitro. Corresponding simulations clearly show that this is not an artifact introduced by the lower signal-tonoise ratio of the dipolar evolution. Possible causes for the observed broadening of the distance distribution between the labels include protein binding changing the DNA conformation, nucleases cleaving the duplex, or DNA melting. It is possible that the observed conformation could continue to change during longer incubation times.

In a very recent study, Prisner, Dötsch, Engels, and co-workers have used a nitroxide that is more stable against reduction in the cellular environment, and therefore, enables longer incubation times. ${ }^{[23]}$ As a model system a 12 bp DNA duplex was investigated. The conformation of the longer duplex featuring a lower relative content of A-T pairs and therewith higher stability than our model system ( $7 \mathrm{bp}$ ) remained conformationally unchanged compared to its in vitro state. This suggests that the observed broad distance distribution of $7 \mathrm{bp}$ DNA duplex is as a result of (partial) DNA melting, in cellulo.
In summary, we have presented here for the first time DEERbased distance measurements in a cellular environment showing conformational changes of a DNA model system with respect to its in vitro state. The findings indicate that in-cell DEER can provide a means to analyze conformations of nucleic acid structures in the cellular environment. While microinjection can be applied to many cells one can utilize transfection reagents as alternatives for delivering spin-labeled nucleic acids into mammalian cells. In addition, it is particularly interesting to apply in-cell DEER to DNA sequences showing a high degree of polymorphism, such as the human telomeric repeat, which is known to adopt-depending on subtle changes of the conditions-drastically different quadruplex conformations. ${ }^{[20,24-26]}$

\section{Acknowledgements}

This study was supported by the DFG (DR 743/2-1), the Center for Mesoscopic Structures, and the Interdisciplinary Research Center Proteostasis within the Exzellenzinitiative. We thank Marco Wassmer for designing the table of contents graphic.

Keywords: EPR distance measurements - EPR spectroscopy in-cell DEER · spin labeling · structure elucidation

[1] W. Hubbell, D. Cafiso, C. Altenbach, Nat. Struct Biol. 2000, 7, 735-739.

[2] G. Jeschke, A. Bender, H. Paulsen, H. Zimmermann, A. Godt, J. Magn. Reson. 2004, 169, 1- 12.

[3] O. Schiemann, N. Piton, Y. Mu, G. Stock, J. W. Engels, T. F. Prisner, J. Am. Chem. Soc. 2004, 126, 5722-5729.

[4] O. Schiemann, N. Piton, J. Plackmeyer, B. E. Bode, T. F. Prisner, J. W. Engels, Nat. Protoc. 2007, 2, 904-923.

[5] G. Jeschke, Ye. Polyhach, Phys. Chem. Chem. Phys. 2007, 9. 1895-1910.

[6] J. E. Banham, C. M. Baker, S. Ceola, I. J. Day, G. H. Grant, E. J. J. Groenen, C. T. Rodgers, G. Jeschke, C. T. Timmel, J. Magn. Reson. 2008, 191, 202218.

[7] H. J. Steinhoff, B. Suess, Methods 2003, 29, 188-195.

[8] E. J. Husted, A. H. Beth, Annu. Rev. Biophys. Biomol. Struct. 1999, 28, $129-153$.

[9] R. Igarashi, T. Sakai, H. Hara, T. Tenno, T. Tanaka, H. Nochio, M. Shirakawa, J. Am. Chem. Soc. 2010, 132, 8228-8229.

[10] a) Z. Serber, P. Selenko, R. Hänsel, S. Reckel, F. Löhr, J. E. Ferrell, Jr., G. Wagner, V. Dötsch, Nature Protocols 2006, 1, 2701 -2709; b) P. Selenko, Z. Serber, B. Gadea, J. Ruderman, G. Wagner, Proc. Natl. Acad. Sci. USA 2006, 103, 11904-11909; c) U. Nienhaus, Angew. Chem. 2008, 120, 9130-9132; Angew. Chem. Int. Ed. 2008, 47, 8992-8994; d) H. Subramanian, P. Pradhan, Y. Liu, I. R. Capoglu, X. Li, J. D. Rogers, A. Heifetz, D. Kunte, H. K. Roy, A. Taflove, V. Backman, Proc. Natl. Acad. Sci. USA 2008, 105, 20118-20123; e) I. Schoen, H. Krammer, D. Braun, Proc. Natl. Acad. Sci. USA 2009, 106, 21649-21654; f) M. Iwai, M. Yokono, N. Inada, J. Minagawa, Proc. Natl. Acad. Sci. USA 2010, 107, 2337-2342; g) C. Policar, J. B. Waern, M. Plamont, S. Clede, C. Mayet, R. Prazeres, J. Ortega, A. Vessieres, A. Dazzi, Angew. Chem. 2011, 123, 890-894; Angew. Chem. Int. Ed. 2011, 50, 860-864.

[11] L. J. Berliner, G. R. Eaton, S. S. Eaton in Biological Magnetic Resonance, Vol. 19: Distance Measurements in Biological Systems by EPR, Kluwer, New York, 2000.

[12] M. M. Dedmon, C. N. Patel, G. B. Young, C. G. Pielak, Proc. Natl. Acad. Sci. USA 2002, 99, $12681-12684$

[13] A. D. Milov, A. B. Ponomarev, Y. D. Tsvetkov, Chem. Phys. Lett. 1984, 110, $67-72$.

[14] R. Ward, A. Bowman, H. El-Mkami, T. Owen-Hughes, D. G. Norman, J. Am. Chem. Soc. 2009, 131, 1348-1349.

[15] G. Jeschke, ChemPhysChem. 2002, 3, 927-932. 
[16] a) A. W. Murray, Methods Cell Biol. 1991, 36, 1-718; b) X. S. Liu, X. J. Liu, Methods Mol. Biol. 2006, 322, 31-43.

[17] A. M. Shafer, T. Kálai, S. Q. Bin Liu, K. Hideg, J. C. Voss, Biochemistry 2004, $43,8470-8482$

[18] K. Shiokawa, K. Tashiro, K Yamana, M. Sameshima, Cell. Differ. 1987, 20 $253-261$.

[19] K. Shiokawa, C. Koga, Y. Ito, M. Shibata, Methods Mol. Biol. 1997, 62, $247-270$.

[20] V. Singh, M. Azarkh, T. E. Exner, J. S. Hartig, M. Drescher, Angew. Chem. 2009, 121, 9908-9910; Angew. Chem. Int. Ed. 2009, 48, 9728-9730.

[21] G. Jeschke, V. Chechik, P. lonita, A. Godt, H. Zimmermann, J. Banham, C. R. Timmel, D. Hilger, H. Jung, Appl. Magn. Reson. 2006, 30, 473-498.

[22] S. Domingo Köhler, M. Spitzbarth, K. Diederichs, T. E. Exner, M. Drescher, J. Magn. Reson. 2011, 208, 167-170.
[23] I. Krstic, R. Hänsel, O. Romaiczyk, J.W. Engels, V. Dötsch, T. F. Prisner, Angew. Chem. 2011, 123, 5176-5180; Angew. Chem. Int. Ed. 2011, 50, 5070-5074.

[24] S. Burge, G. N. Parkinson, P. Hazel, A. K. Todd, S. Neidle, Nucleic Acids Res. 2006, 34, 5402-5415.

[25] D. J. Patel, A. T. Phan, V. Kuryavyj, Nucleic Acids Res. 2007, 35, 74297455.

[26] J. Dai, M. Carver, D. Yang, Biochemie 2008, 90, 1172-1183. 